\title{
Analisis Video Likes to Followers Ratio Tiktok Pada 5 Brand Sneakers Lokal Terbaik di Indonesia
}

\author{
Gusti Agung Adityadarma \\ agungaditiya2007@gmail.com
}

\begin{abstract}
Tiktok is a social media application from China that was founded by a company calledByteDance in 2016. This application provides many features such as videos, filters, music and live broadcast features. Tiktok has more than 850 million users from various countries, in Indonesia Tiktok users have reached more than 30 million users which makes this application the most popular social media in Indonesia. With the popularity of Tiktok in Indonesia, many brands take the opportunity to make Tiktok as a marketing platform for their products. One of them is a local sneaker brand that uses Tiktok as one of their marketing media, here are the 5 best local sneaker brands in Indonesia: Compass, Heiden heritage, Patrobas, Getzke and Ventella. This research aims to determine the performance of each of the five local sneaker brand's Tiktok accounts by using the video likes to followers ratio. Exploratory quantitative methods were used in this research. The result from this study was indicate that the Ventella sneaker brand is the brand that has the best account performance of the five local sneaker brands.
\end{abstract}

\begin{abstract}
ABSTRAK
Tiktok merupakan aplikasi media sosial asal tiongkok yang didirikan oleh perusahaan bernama ByteDance pada tahun 2016. Aplikasi ini menyediakan banyak fitur seperti video, filter, musik sampai fitur siaran langsung. Tiktok memiliki lebih dari 850 juta pengguna dari berbagai negara, di Indonesia sendiri pengguna Tiktok telah mencapai lebih dari 30 juta pengguna yang menjadikan aplikasi ini menjadi media sosial paling popular di Indonesia. Dengan kepopuleran aplikasi Tiktok di Indonesia membuat banyak brand mengambil kesempatan untuk menjadikan Tiktok sebagai media untuk mempromosikan produk mereka. Salah satunya adalah brand sneakers lokal yang menjadikan Tiktok sebagai salah satu media promosi mereka, berikut adalah 5 brand sneakers lokal terbaik di Indonesia: Sepatu Compass, Heiden heritage, Patrobas, Getzke dan Ventella. Penelitian ini bertujuan untuk mengetahui performa dari setiap akun Tiktok kelima brand sneakers lokal tersebut dengan menggunakan video likes to followers ratio. Pada penelitian ini digunakan metode eksploratif kuantitatif. Dari Penelitian ini didapatkan hasil bahwa brand sneakers Ventella merupakan brand yang memiliki kredibilitas performa akun terbaik dari kelima brand sneakers lokal tersebut.
\end{abstract}

Keyword : Tiktok Account Credibility, Social Media Tiktok Analysis, Video Likes to Followers Ratio, Brand Sneakers Lokal Indonesia 


\section{PENDAHULUAN}

Seiring dengan pesatnya perkembangan teknologi, komunikasi antar remaja di lingkungan sosial maupun di lingkungan sekolah sekarang sudah menguasai ilmu teknologi yang mengunakan jaringan internet, yaitu media sosial (Oktaheriyani, Wafa, and Shadiqien 2020). Media sosial merupakan media online yang digunakan sebagai sarana untuk berkomunikasi jarak jauh secara daring, selain untuk berkomunikasi pengguna media sosial juga dapat berbagi, menghibur diri, bahkan bisa belajar melalui media sosial karena saat ini sudah banyak terdapat konten-konten edukasi di berbagai platform media sosial. Media sosial yang saat ini banyak digunakan adalah TikTok, Instagram, facebook, twitter, youtube dan masih banyak lagi.

Tahun 2021 di Indonesia, dimasa pandemi Covid-19 ini membuat pengguna media sosial bertambah pesat karena pemerintah menerapkan semua kegiatan dilakukan dirumah yang membuat masyarakat mencari cara agar tidak jenuh dirumah. Salah satu yang sedang populer saat ini adalah aplikasi TikTok yang memliki pengguna sebanyak lebih dari 850 juta unduhan berdasarkan data dari Apptopia pada tahun 2020. Di Indonesia sendiri setidaknya ada lebih dari 30 juta penduduk di Indonesia yang menggunakan aplikasi Tiktok. Media sosial ini merupakan salah satu platform asal Tiongkok, yang pertama kali diluncurkan pada tahun 2016 oleh perusahaan bernama ByteDance. Walaupun dulu aplikasi ini banyak ditentang di berbagai negara termasuk di Indonesia karena dianggap kurang mendidik oleh masyarakat, namun sekarang Tiktok menjadi salah satu media sosial yang terpopuler di Indonesia. Aplikasi ini banyak menyajikan fitur-fitur seperti video, lagu, stiker, dan lain-lain sehingga para pengguna dapat beradu model dan gaya baik dari kalangan artis hingga masyarakat biasa yang ingin membagikan video olah kreativitasnya (Madhani et al. 2021).

Dengan kepopuleran aplikasi media sosial TikTok saat ini, membuat banyak brandmenggunakan aplikasi ini sebagai sarana mereka untuk mempromosikan produknya. Salah satunya adalah brand sneakers lokal yang ada di Indonesia, produk sneakers buatan dalam negrikini semakin banyak diminati oleh remaja di Indonesia. Berikut adalah 5 brand sneakers lokal terbaik di Indonesia, antara lain : Compass, Heiden heritage, Patrobas, Getzke dan Ventella ("5 Sepatu Sneakers Lokal yang Banyak Digemari Anak Muda - Kabarjoglosemar, 2020").

Untuk dapat mengetahui kredibilitas performa dari kelima akun TikTok brand sneakers lokal terbaik ini, maka dilakukanlah penelitian ini dengan menggunakan metode eksploratif kuantitatif, yang akan menggunakan rasio-rasio yang ada pada aplikasi TikTok. (Permana and Meinarni 2021) menjelaskan bahwa terdapat 17 rasio yang ada pada sosial media TikTok dan relevan digunakan sebagai media ukur kredibilitas akun yang ada. Pada penelitian ini, peneliti hanya berfokus untuk menghitung kredibilitas dari Video Likes to Followers Ratio pada akun TikTok 5 brand sneakers lokal terbaik di Indonesia.

\section{TINJAUAN PUSTAKA}

Perkembangan teknologi terjadi begitu pesat dalam beberapa tahun belakangan ini, media sosial merupakan salah satu contoh dari pesatnya perkembangan teknologi saat ini. Hampir semua kalangan di era ini pasti mempunyai akun media sosial seperti tiktok, Instagram, facebook, 
twitter atau platform media sosial lain. Aplikasi yang dapat kita unduh secara gratis ini membuat kita dapat berinteraksi dengan sesama pengguna internet, entah itu berupa pesan, foto, video dan sebagainya. Itu merupakan salah satu alasan mengapa pengguna media sosial saat ini sangat banyak. Di Indonesia, penetrasi pengguna media sosial terus meningkat menjadi 59\% dari 272,1 juta total penduduk Indonesia. (Moedia 2020)

Tiktok adalah salah satu media sosial dengan pengguna aktif terbanyak, penggunanya mengalami peningkatan tiga kali lipat dalam setahun di 2021. Aplikasi yang memfasilitasi penggunanya untuk merekam, memasukkan suara, gambar, stiker, filter dan editing,membagikan video yang sudah dibuat, dan ditransmisi ke media lainnya yang mendukung ini resmi masuk ke Indonesia pada tahun 2016. (islamiyah 2020). Salah satu penyebab meningkatnya pengguna TikTok hingga tiga kali lipat adalah karena pandemi covid-19, karena masyarakat menghabiskan kebanyakan waktunya dirumah sesuai anjuran pemerintah dan mereka memilih tiktok sebagai penghilang rasa bosan. TikTok juga menjadi kategori aplikasi paling menghibur (Adawiyah 2020).

Banyaknya pengguna TikTok di masa pandemi ini membuat beberapa brand memanfaatkan tiktok sebagai media pemasaran mereka, dengan cara membuat konten menarik di akun tiktok mereka yang berkaitan dengan produk yang mereka jual, dan tak jarang juga mereka mengikuti trend yang sedang dibicarakan oleh banyak orang. Salah satu contoh yaitu brand fashion mulai dari brand baju hingga sepatu. Dengan adanya tren fashion yang mengikuti perkembangan zaman membuat banyak masyarakat baik perempuan maupun laki-laki tergiur untuk berbelanjahanya untuk memiliki barang yang sedang ramai dipasaran atau dengan kata lain booming. (Purnamasari and Tutiasri 2021).

Promosi mempengaruhi aktivitas penjualan, karena promosi dapat mempengaruhi tingkat penjualan suatu produk barang (Rifaldi 2019). Maka dari itu diperlukan akun dengan performa yang baik. Untuk melihat apakah sebuah akun memiliki performa / kredibilitas yang baik diperlukan adanya analisis dengan membandingkan beberapa rasio. Hal ini penting karena dari hasil analisis dapat dijadikam evaluasi oleh pemilik akun untuk meningkatkan performa akunnya sehingga dapat meningkatkan penjualan produk mereka.

\section{Metode Penelitian}

Pada penelitian ini, digunakan metode eksploratif kuantitatif agar dapat mengetahui kredibilitas dari setiap akun tiktok 5 brand sneakers lokal terbaik di Indonesia. Metode penelitian eksploratif merupakan penelitian yang bertujuan untuk menggali secara luas tentang sebab-sebab atau halhal yang mempengaruhi terjadinya sesuatu dan dipakai manakala kita belum mengetahui (Nurlailiyah 2016).

Penelitian ini bertujuan untuk dapat mengetahui performa dari kelima akun tiktok brand sneakers lokal terbaik di Indonesia. Untuk dapat melihat performa akun yang mendapatkan hasil terbaik, maka dilakukan beberapa langkah-langkah pada penelitian ini :

\section{Menentukan Objek Yang Akan Dianalisa Dengan Mengeksplorasi Website.}


Untuk mendapatkan objek yang akan di Analisa, peneliti mengeksplorasi beberapa website yang menyediakan informasi yang berkaitan dengan objek yang akan di teliti. Setelah mendapatkan nama-nama brand sneakers lokal yang akan dijadikan objek untuk dianalisa pada halaman website, langkah yang dilakukan berikutnya adalah mencari akun tiktok kelima brand sneakers lokal tadi.

\section{Menghitung Jumlah Rata-rata Variabel Dari Kelima Brand Sneakers Lokal.}

Di tahap ini, peneliti akan menghitung nilai rata-rata variabel video likes dan jumlah keseluruhan followers pada setiap akun tiktok brand sneakers lokal. Variabel merupakan indikator terpenting yang menentukan keberhasilan penelitian, sebab variabel penelitian merupakan objek penelitian atau menjadi titik perhatian suatu penelitian (Syaifullah, 2016). Langkah ini dilakukan dengan menggunakan 10 video tiktok pada masing-masing akun kemudian dihitung rata-rata jumlah likes ke 10 video dan jumlah followers pada kelima akun tiktok brand sneakers lokal terbaik.

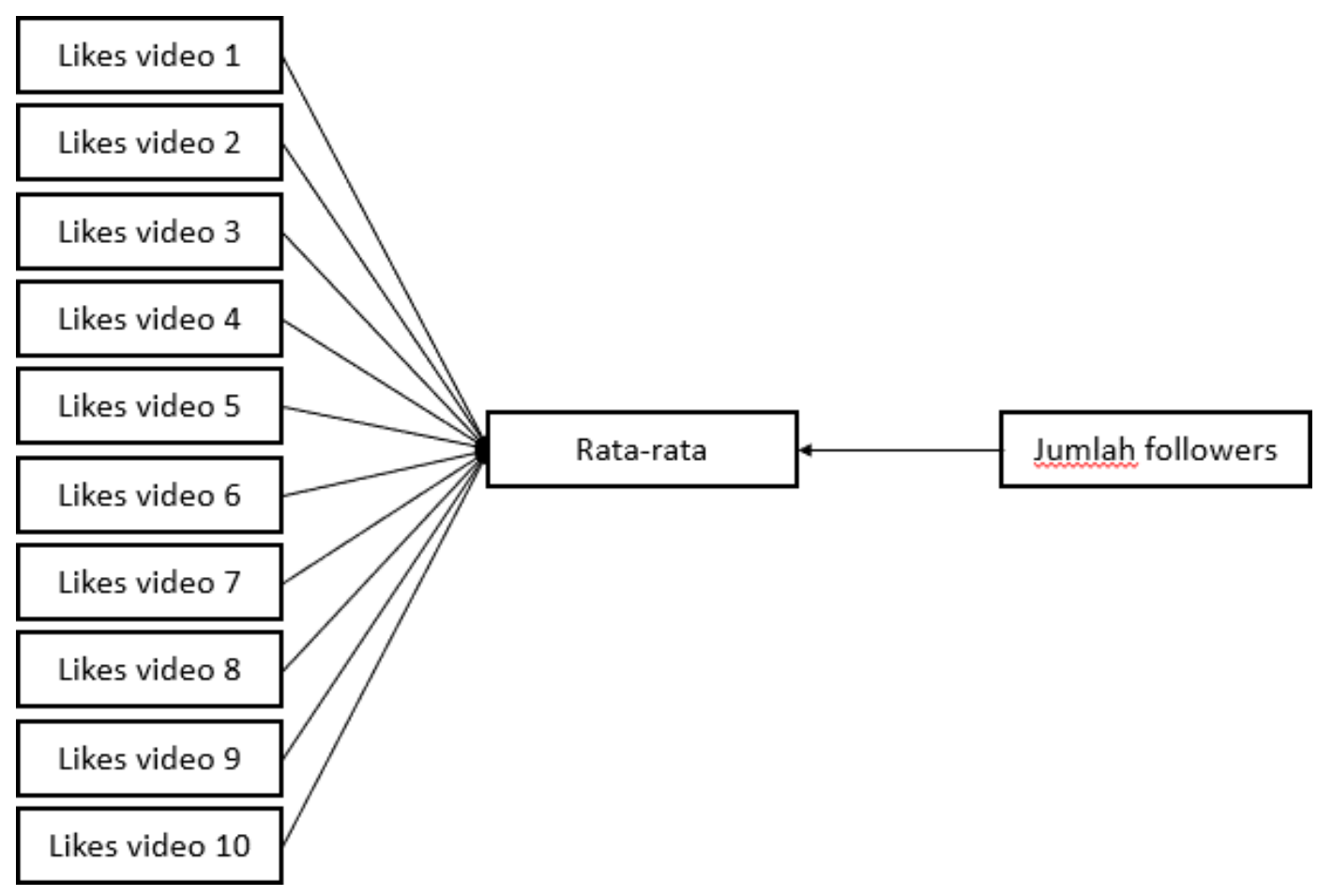

Gambar 1 Rata-rata Variabel

\section{Menghitung Nilai Kredibilitas Rasio}

Agar dapat mengetahui nilai kredibilitas dari video likes to followers ratio, peneliti menghitung dengan membagi jumlah rata-rata video likes dengan jumlah followers. Misalnya jumlah rata-rata video likes pada akun A adalah 200 dan memiliki followers sebanyak 600 maka dapat dihitung dengan cara 200:600 = 0,3 maka kita akan mendapat nilai dari video likes to followers ratio yaitu 0,3 .

\section{Menentukan Peringkat Pada Akun Yang Dianalisa}

Tahap ini merupakan tahap terakhir dalam penelitian ini yaitu dengan menentukan peringkat dari hasil rasio yang telah dihitung, untuk dapat menentukan peringkat kita harus mengetahui karakteristik dari rasio yang diteliti. Jika karakteristik rasio merupakan 
rendah, maka objek yang memiliki nilai terendah akan mendapatkan angka 5 dan objek yang memiliki nilai tertinggi akan mendapatkan angka 1. Begitu juga sebaliknya, untuk video likes to followers ratio memiliki karakteristik tinggi, maka jika objek mendapat nilai tinggi akan mendapat angka 5 dan yang mendapat nilai terendah akan mendapatkan angka 1 .

\section{HASIL DAN PEMBAHASAN}

Berikut adalah lima akun tiktok dari kelima brand sneakers lokal terbaik di Indonesia, diantaranya:

1) Sepatu Compass

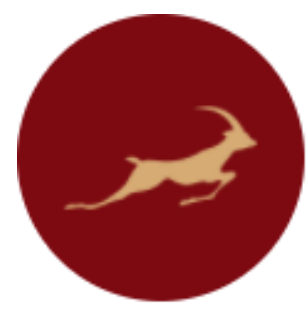

\section{admincompass}

Sepatu Compass

\section{Follow}

0 Following 9181 Followers 159.2K Likes

Toko Online Resmi Compass ${ }^{\oplus}$ di Tokopedia:

$\mathcal{O}$ tokopedia.link/sepatucompass

Gambar 2. Akun Tiktok Sepatu Compass

Sumber : https://www.tiktok.com/@admincompass? (akses pada 21-10-2021)

2) Heiden Heritage

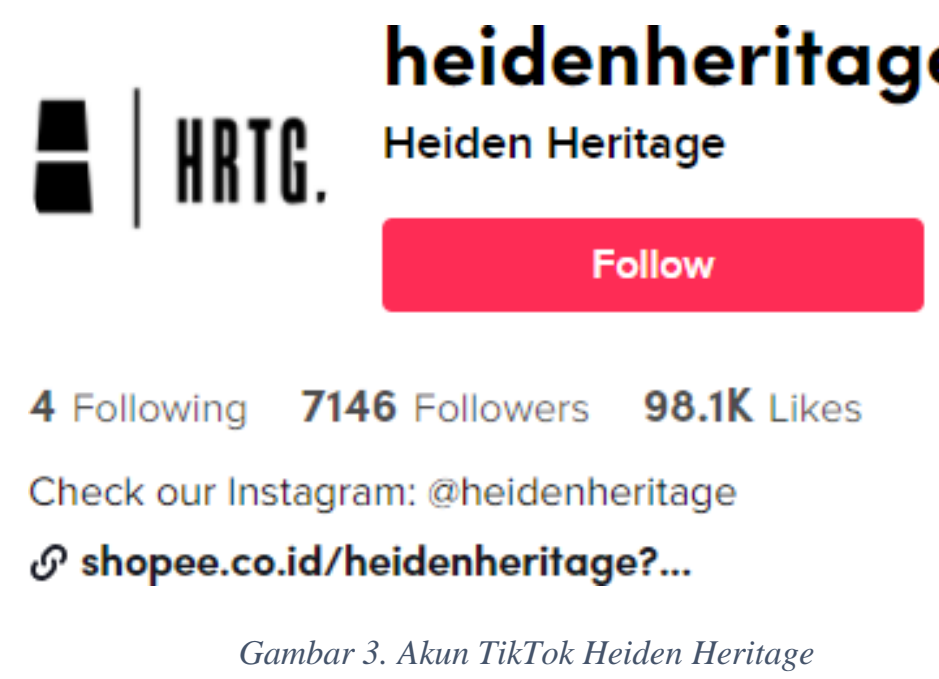

Sumber : https://www.tiktok.com/@heidenheritage? (akses pada 21-10-2021) 


\section{3) Patrobas}

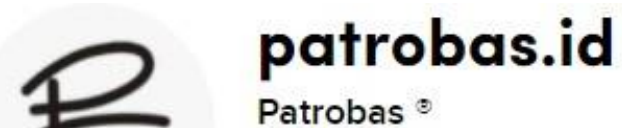

Follow

14 Following $\mathbf{5 9 2 2}$ Followers $76.6 \mathrm{~K}$ Likes

Price \& Benefit. Sepatu vulcanized berkualitas harga terjangkau

1 Order klik 1

O patrobas.id/links/

Gambar 4. Akun TikTok Patrobas

Sumber : https://www.tiktok.com/@ patrobas.id? (akses pada 21-10-2021)

\section{4) Getzke}

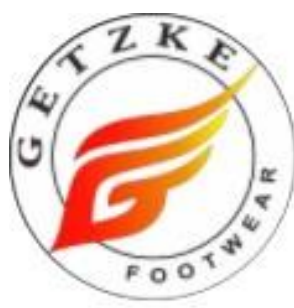

\section{getzke.id}

Getzke.id

Follow

17 Following 2300 Followers $10.4 \mathrm{~K}$ Likes

GETZKE.ID Bangga Buatan Indonesia

$\odot$ page.co.id/Getzke

Gambar 5. Akun Tiktok Getzke

Sumber : https://www.tiktok.com/@getzke.id? (akses pada 21-10-2021) 


\section{5) Ventela}

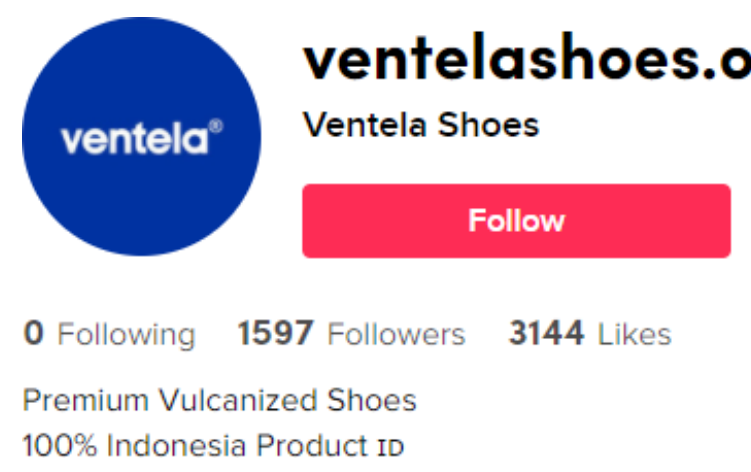

Gambar 6. Akun Tiktok Ventela

Sumber : https://www.tiktok.com/@ventelashoes.official? (akses pada 21-10-2021)

Dari Dari lima akun TikTok brand sneakers lokal terbaik di Indonesia, peneliti menemukan nilai dari setiap variabel yang ada untuk menghitung rasio video likes to followers pada setiap akun. Terdapat 7 variabel dalam akun TikTok, antara lain:

1. Likes

2. Followers

3. Following

4. Video Likes

5. Video Comments

6. Video Share

7. Video Views

Dari ketujuh variabel tersebut peneliti hanya fokus untuk menemukan hasil dari 2 variabel, yaitu :

1. Video Likes

2. Followers

Dari kedua variabel diatas kemudian dianalisis untuk mencari nilai rata-rata dari variabel video likes dan variabel followers. Peneliti menghitung nilai rata-rata dari variabel video likes dan variabel followers video dengan cara mengambil 10 postingan kemudian dihitung untuk mencari nilai rata-rata dari masing-masing variabel. Di bawah ini adalah tabel nilai rata-rata dari masing-masing akun tiktok brand sneakers lokal di Indonesia, yaitu :

Tabel 1. Analisa Nilai Rata-Rata Nilai Variabel Video Likes dan Followers Akun TikTok Sepatu Compass

\begin{tabular}{|c|r|r|}
\hline No & Video Likes & Followers \\
\hline 1 & 463 & 9,181 \\
\hline 2 & 2,739 & 9,181 \\
\hline
\end{tabular}




\begin{tabular}{|c|r|r|}
3 & 536 & 9,181 \\
\hline 4 & 148 & 9,181 \\
\hline 5 & 45 & 9,181 \\
\hline 6 & 13,600 & 9,181 \\
\hline 7 & 185 & 9,181 \\
\hline 8 & 95 & 9,181 \\
\hline 9 & 216 & 9,181 \\
\hline 10 & 362 & 9,181 \\
\hline Total & $\mathbf{1 , 8 3 9}$ & $\mathbf{9 , 1 8 1}$ \\
\hline
\end{tabular}

Sumber : Pengolah Data Excel

Tabel 2. Analisa Nilai Rata-Rata Nilai Variabel Video Likes dan Followers Akun TikTok Heiden Heritage

\begin{tabular}{|c|r|r|}
\hline No & Video Likes & Followers \\
\hline 1 & 11 & 7,146 \\
\hline 2 & 1,384 & 7,146 \\
\hline 3 & 6 & 7,146 \\
\hline 4 & 49 & 7,146 \\
\hline 5 & 799 & 7,146 \\
\hline 6 & 1,292 & 7,146 \\
\hline 7 & 6,540 & 7,146 \\
\hline 8 & 36 & 7,146 \\
\hline 9 & 21 & 7,146 \\
\hline 10 & 68 & 7,146 \\
\hline Total & $\mathbf{1 , 0 2 1}$ & $\mathbf{7 , 1 4 6}$ \\
\hline \multicolumn{2}{|c|}{ Sumber Pengolah Data Excel } \\
\hline
\end{tabular}

Sumber : Pengolah Data Excel

Tabel 3. Analisa Nilai Rata-Rata Nilai Variabel Video Likes dan Followers Akun TikTok Patrobas

\begin{tabular}{|c|r|r|}
\hline No & Video Likes & Followers \\
\hline 1 & 3,069 & 5,922 \\
\hline 2 & 112 & 5,922 \\
\hline 3 & 1,104 & 5,922 \\
\hline 4 & 828 & 5,922 \\
\hline 5 & 36 & 5,922 \\
\hline 6 & 56 & 5,922 \\
\hline 7 & 46 & 5,922 \\
\hline 8 & 3,379 & 5,922 \\
\hline 9 & 219 & 5,922 \\
\hline 10 & 60 & 5,922 \\
\hline Total & 891 & 5,922 \\
\hline
\end{tabular}

Sumber : Pengolah Data Excel 
Tabel 4. Analisa Nilai Rata-Rata Nilai Variabel Video Likes dan Followers Akun TikTok Getzke

\begin{tabular}{|c|r|r|}
\hline No & Video Likes & Followers \\
\hline 1 & 16 & 2,300 \\
\hline 2 & 12 & 2,300 \\
\hline 3 & 8 & 2,300 \\
\hline 4 & 1,637 & 2,300 \\
\hline 5 & 20 & 2,300 \\
\hline 6 & 13 & 2,300 \\
\hline 7 & 23 & 2,300 \\
\hline 8 & 76 & 2,300 \\
\hline 9 & 37 & 2,300 \\
\hline 10 & 770 & 2,300 \\
\hline Total & \multicolumn{2}{|c|}{2,300} \\
\hline \multicolumn{2}{|c|}{ Sumber : Pengolah Data Excel } \\
\hline
\end{tabular}

Tabel 5. Analisa Rata-Rata Nilai Variabel Video Likes dan Followers Akun TikTok Ventela

\begin{tabular}{|c|r|r|}
\hline No & Video Likes & Followers \\
\hline 1 & 141 & 1,597 \\
\hline 2 & 257 & 1,597 \\
\hline 3 & 1,922 & 1,597 \\
\hline 4 & 769 & 1,597 \\
\hline Total & $\mathbf{7 7 2}$ & $\mathbf{1 , 5 9 7}$ \\
\hline
\end{tabular}

Setelah menghitung nilai rata-rata tersebut, maka akan menemukan hasil akhir nilai rata-rata dari variabel video likes dan followers

Tabel 6. Nilai Variabel Pada Akun TikTok Top 5 Vendor Smartphone di Indonesia Q1-2021

\begin{tabular}{|c|c|c|c|c|c|}
\hline Variable & $\begin{array}{c}\text { Sepatu } \\
\text { Compass }\end{array}$ & $\begin{array}{c}\text { Heiden } \\
\text { Heritage }\end{array}$ & Patrobas & Getzke & Ventela \\
\hline Video Likes & 1839 & 1021 & 891 & 770 & 772 \\
\hline Followers & 9181 & 7146 & 5922 & 2300 & 1597 \\
\hline
\end{tabular}

Sumber : Pengolah Data Excel

Pada akun TikTok terdapat 17 rasio yang relevan digunakan untuk mengukur kredibilitas pada masing-masing akun. Namun pada penelitian kali ini hanya berfokus untuk menghitung Video Likes to Followers Ratio. Untuk menghitung kredibilitas dari masing-masing akun TikTok 
setiap brand sneakers, peneliti menghitung dengan cara : variabel 1 akan dibagi dengan variabel 2, sehingga ditemukan hasil analisisa dari rasio tersebut.

Tabel 7. Hasil Perhitungan Rasio Akun TikTok

\begin{tabular}{|c|l|c|c|c|c|c|}
\hline No & \multicolumn{1}{|c|}{ Ratio } & $\begin{array}{c}\text { Sepatu } \\
\text { Compass }\end{array}$ & $\begin{array}{c}\text { Heiden } \\
\text { Heritage }\end{array}$ & Patrobas & Getzke & Ventela \\
\hline 1 & $\begin{array}{l}\text { Video Likes to } \\
\text { Followers Ratio }\end{array}$ & 0.200304978 & 0.287573468 & 0.150455927 & 0.33478261 & 0.483406387 \\
\hline
\end{tabular}

Sumber : Pengolah Data Excel

Video Likes to Followers Ratio memiliki karakteristik yang tinggi, artinya semakin tinggi nilai yang dihasilkan maka semakin baik kredibilitas dari performa akun tersebut. Untuk memberikan peringkat pada masing-masing brand sneakers, peneliti memberikan angka 5 kepada vendor yang mendapatkan nilai tertinggi dan angka 1 untuk vendor smartphone yang mendapatkan nilai terendah. Berikut merupakan tabel urutan nilai yang dihasilkan oleh masingmasing brand sneakers.

Tabel 8. Nilai Rasio Akun TikTok 5 Brand Sneakers Lokal Terbaik

\begin{tabular}{|l|c|c|c|c|c|}
\hline \multirow{2}{*}{\multicolumn{1}{|c|}{ RATIO }} & \multicolumn{5}{|c|}{ NILAI } \\
\cline { 2 - 6 } & $\begin{array}{c}\text { Sepatu } \\
\text { Compass }\end{array}$ & $\begin{array}{c}\text { Heiden } \\
\text { Heritage }\end{array}$ & Patrobas & Getzke & Ventela \\
\hline $\begin{array}{l}\text { Video Likes to } \\
\text { Followers Ratio }\end{array}$ & 2 & 3 & 1 & 4 & 5 \\
\hline
\end{tabular}

Sumber : Pengolah Data Excel

Dari tabel Nilai Rasio Akun TikTok 5 Brand Sneakers Lokal Terbaik di Indonesia dapat disimpulkan bahwa akun Ventela mendapatkan nilai tertinggi untuk rasio Video Likes to Followers. Sedangkan akun TikTok Patrobas mendapatkan nilai terendah untuk rasio ini. Jadi, pada penelitian ini Ventela memiliki kredibilitas performa yang lebih baik dibandingkan dengan vendor smartphone yang lainnya.

\section{KESIMPULAN}

Tujuan dari penelitian ini adalah untuk mengetahui kredibilitas performa dari setiap akun TikTok Brand Sneakers Lokal Terbaik dengan menggunakan Video Likes to Followers Ratio. Kelima brand sneakers tersebut diantaranya : Sepatu Compass, Heiden Heritage, Patrobas, Getzke dan Ventela. Dari kelima brand sneakers tersebut dapat disimpulkan bahwa : 
1. Peringkat pertama diraih oleh brand Ventela dengan nilai tertinggi yaitu 0.483406387

2. Peringkat kedua diraih oleh brand Getzke dengan nilai 0.33478261

3. Peringkat ketiga diraih oleh brand Heiden Heritage dengan nilai 0.287573468

4. Peringkat keempat diraih oleh brand Sepatu Compass dengan nilai 0.200304978

5. Peringkat kelima diraih oleh brand Patrobas dengan nilai terendah yaitu 0.15045592 


\section{DAFTAR PUSTAKA}

Adawiyah, Dwi Putri Robiatul. 2020. "Pengaruh Penggunaan Aplikasi TikTok Terhadap Kepercayaan Diri Remaja Di Kabupaten Sampang.” Jurnal Komunikasi 14 (2): 135-48. https://doi.org/10.21107/ilkom.v14i2.7504.

islamiyah, hanifah. 2020. "PENGARUH INTENSITAS MENGGUNAKAN TIK TOK TERHADAP PERILAKU BODY SHAMING ANAK." ORASI: Jurnal Dakwah Dan Komunikasi 11 (2): 205-18. https://doi.org/10.24235/ORASI.V11I2.6640.

Madhani, Luluk Makrifatul, Indah Nur, Bella Sari, M Nurul Ikhsan Shaleh, Keluarga Mahasiswa, Islam Kehutanan, Dakwah Hijrah Mahasiswa, Excellent Community, and Perilaku Islami. 2021. "DAMPAK PENGGUNAAN MEDIA SOSIAL TIKTOK TERHADAP PERILAKU ISLAMI MAHASISWA DI YOGYAKARTA” 3: 604-24.

Moedia, A. 2020. “5 Media Sosial Paling Popular Di Dunia Pada Q2 2020,” 2020.

Nurlailiyah, Siti. 2016. "Studi Dampak Facebook Terhadap Perubahan Pola Komunikasi Antar Pribadi Mahasiswa IAIN Jember."

Oktaheriyani, Desy, M Ali Wafa, and Shen Shadiqien. 2020. “Analisis Perilaku Komunikasi Pengguna Media Sosial TikTok (Studi Pada Mahasiswa Fakultas Ilmu Sosial Dan Ilmu Politik UNISKA MAB Banjarmasin )." Jurnal Ilmu Sosial Dan Ilmu Politik, 7-52. http://eprints.uniska-bjm.ac.id/id/eprint/3504.

Purnamasari, Nurjihan Pricillia, and Ririn Puspita Tutiasri. 2021. “Analisis Resepsi Remaja Perempuan Terhadap Gaya Hidup Berbelanja Fashion Melalui Tayangan Video 'Belanja Gak Aturan' Dalam Akun Tiktok @handmadeshoesby.” Jurnal Representamen 7 (01). https://doi.org/10.30996/REPRESENTAMEN.V7I01.5129.

Rifaldi, Wardinal. 2019. "PEMANFAATAN MEDIA SOSIAL INSTAGRAM SEBAGAI MEDIA PROMOSI PEMASARAN MAKANAN DI BANJARBARU (Studi Pada Akun Instagram @burgerberkahbersama).”

SYAIFULLAH, S. 2016. "Pengaruh Partisipasi Anggota Dan Pelayanan Kredit Terhadap Keberhasilan Usaha Koperasi Mekar Sari DPRD Sulawesi Selatan." Angewandte Chemie International Edition, 6(11), 951-952. 13 (April): 15-38. http://eprints.unm.ac.id/4286/.

Permana, I Putu Hendika, and Ni Putu Suci Meinarni. 2021. "Ratio Analysis on Tiktok (Social Media) for Qualitative Research Using Explorative Methods." Jurnal Ekonomi \& Bisnis JAGADITHA 8 (1): 30-38. https://doi.org/10.22225/JJ.8.1.2944.30-38

"5 Sepatu Sneakers Lokal yang Banyak Digemari Anak Muda - Kabar Joglo Semar" n.d. Accessed October 20, 2021. https://kabarjoglosemar.pikiran-rakyat.com/gaya-hidup/pr73726333/5-sepatu-sneakers-lokal-yang-banyak-digemari-anak-muda. 